\title{
What Motivates Participation in Violent Political Action
}

\section{Selective Incentives or Parochial Altruism?}

\author{
Jeremy Ginges ${ }^{a}$ and Scott Atran ${ }^{b}$ \\ ${ }^{a}$ New School for Social Research, New York, New York 10011, USA \\ ${ }^{b}$ Centre National de la Recherche Scientifique - Institut Jean Nicod, Paris, France; \\ University of Michigan, Ann Arbor, Michigan 48109, USA; and John Jay College of \\ Criminal Justice, New York, New York 10019, USA
}

\begin{abstract}
In standard models of decision making, participation in violent political action is understood as the product of instrumentally rational reasoning. According to this line of thinking, instrumentally rational individuals will participate in violent political action only if there are selective incentives that are limited to participants. We argue in favor of an alternate model of political violence where participants are motivated by moral commitments to collective sacred values. Correlative and experimental empirical evidence in the context of the Israeli-Palestinian conflict strongly supports this alternate view.
\end{abstract}

Key words: political violence; terrorism, sacred values; Palestinians; settlers

\section{Introduction}

Why do individuals sacrifice their own selfinterest to participate in violent collective actions? Participation is costly and risky to the individual, and collective success leads to indiscriminate collective benefits. For example, if collective action secures the independence of an oppressed national group, all members of the group benefit equally. Thus, from the perspective of individual-level instrumental rationality, the most effective strategy is to take a "free ride" ${ }^{1}$ on the actions of others ${ }^{1}$ unless participants are offered "selective incentives" 24 where contributors to collective actions accrue private or selective benefits that are additional to the public benefits of a successful rebellion. This perspective does not ignore the importance of ideology ${ }^{5}$ but characterizes a high level of commitment to ideology as a willingness to

Address for correspondence: Jeremy Ginges, Department of Psychology, New School for Social Research, 80 Fifth Avenue, New York, NY 10011. Voice: 212-229-5727 ext.3012. gingesj@newschool.edu delay selective rewards to the future when victory is obtained. ${ }^{6}$

The focus of our research program has been to investigate the extent to which this type of cost-benefit decision making characterizes violent intergroup conflicts. Our findings suggest that decisions in these types of conflicts are more akin to intuitive moral decision making ("is this mandated or prohibited?") than to utility maximization. In one line of research we have investigated what happens when people cognitively transform issues under dispute into sacred values, values to which they declare a moral commitment that precludes material trade-offs. For instance, this may happen when people transform land from a fungible resource into "holy land." We have demonstrated that people in such cases often resist any attempts to balance a compromise over such values with material incentives. Moreover, opposition to compromise over sacred values actually increases in response to materially improved offers. ${ }^{7}$ However, a purely symbolic (but often difficult and painful) act by the counterpart, 
such as an apology for past wrongs, can induce greater willingness to compromise. ${ }^{7-9}$

In this paper we report the results of research investigating the motivations of individuals who take part in violent collective actions. As noted in the opening, the dominant model assumes that such participation is motivated by selective private incentives. According to this approach, while many people might be outraged by, for example, a violation of their sacred value, those who participate in violent collective reaction will do so because they expect to receive private benefits later. Thus, individuals participate in collective action in response to salient offers of private benefits that disproportionately motivate them compared to nonparticipating supporters. We argue to the contrary and present empirical evidence to support our case that participation is more a function of "parochial altruism"10,11 or collective commitment than selective incentives. Before discussing our own data, we briefly review the existing empirical evidence.

\section{Empirical Evidence: The Selective Incentives Hypothesis}

Those who stress the important role of personal instrumental incentives to collective actions often point to aggregate data that seem to show that individual "greed" trumps collective "grievances" as a cause of civil war. On one hand, proxies for typical causes of ideological grievances, including income inequality, political inequality, ethnic divisions, and religious divisions, do not do an adequate job of explaining the cross-country likelihood of civil war. ${ }^{12} \mathrm{On}$ the other hand, cross-country comparisons reveal a negative relationship between per capita income and the likelihood of ethnic or civil war and that lower rates of gross domestic product (GDP) growth, coupled with increased opportunities of looting, increases the likelihood of civil war onset. ${ }^{13}$ The implication is that high levels of material needs (indicated by low GDP growth) coupled with incentives to satisfy those needs (indicated by opportunity for looting) are consistent with some of the premises identified above - salient selective incentives and the motivation to obtain those incentives appear to explain why some places see more conflict than others. There is equivocal evidence that this relationship might be mirrored at the individual level. MacCulloch reports analysis of microlevel data sets that show a negative relationship between an individual's relative income level within a country and his or her desire for revolution. ${ }^{14}$

However, two shortcomings of this evidence are apparent. First, actual levels of things that may cause ideological collective grievances (such as income inequality) may be weakly correlated with perceived grievance. In fact, converging social psychological research detail the way oppressed groups internalize stereotypes that justify their oppression, ${ }^{15,16}$ leading to an alternative explanation of why actual inequalities may not predict likelihood of civil conflictthe effect of inequality is likely moderated by the perceived illegitimacy of such inequality. ${ }^{17}$ Second, MacCulloch's analysis did not control for potentially confounding factors, such as ethnicity or identification with high- or low-status groups. ${ }^{14}$ Thus, we cannot know whether relative economic status is itself a cause of support for rebellion or instead a proxy for other potentially important variables. In fact, focusing on economic indicators leads to an incomplete test of the hypothesis that people require individuallevel incentives to participate in collective action.

Other potential selective incentives may include the maintenance or enhancement of individual status within the collective. Tropp and Brown report research examining the importance of these types of incentives in the context of participation in collective campaigns for women's rights in the USA. ${ }^{18}$ They found that the more people believed participation might enhance their own self-esteem or selfimportance, the more likely they were to express interest in and involvement in collective action. However, these measures might 
have conflated self-enhancement motives with ideology. Many collective actions carried out by women's rights movements are specifically designed to raise self-esteem of women. Thus, a belief that participation will increase self-esteem might actually be measuring accordance with the ideology of the women's movement rather than (or as well as) selective emotional incentives to participate. This alternate explanation of Tropp and Brown's findings is supported by other studies measuring participation in a greater variety of collective actions across cultures that show expected social rewards do not predict participation in collective action. $^{19,20}$

\section{Empirical Evidence: The Collective Commitment Hypothesis}

There is some anecdotal evidence to suggest that selective incentives may not be necessary to motivate violent political action. To give an extreme example, Jewish resistance in the Warsaw Ghetto during World War II emerged only when death was deemed unavoidable. ${ }^{21}$ In such a case it is difficult to see how fighting was motivated by a cost-benefit analysis as there was nothing to win by fighting. Current empirical evidence for the collective commitment (or parochial altruism) hypothesis is insufficient, although compelling. Research has linked individually costly cooperation with a collective to high levels of identification with it. ${ }^{22,23}$ People identify themselves on collective levels in addition to individual ones, ${ }^{24-27}$ and there is a general tendency to act in ways that have collective benefits irrespective of individual-level benefits even when those collectives are meaningless laboratory constructions. ${ }^{17,28}$ Identification with a collective is a reliable predictor of protest participation, ${ }^{29}$ and support for political protest may indeed be fostered by perceptions about collective rather than individual economic and political circumstances. ${ }^{30-34}$

Although clearly important, this research is not definitive for our purpose. Proponents of the selective incentives argument do not claim that collective identification is unassociated with collective action; they merely claim that collective identification is insufficient to motivate individual participation in such action. In addition, a plausible interpretation of the above evidence is that the level of collective identification might simply be a proxy for vulnerability to informal social incentives that encourage participation. In other words, to the extent that a person identifies highly with a group, he or she is more likely to be sensitive to informal selective incentives. Hence there is little empirical evidence that supports the idea that collective identification is sufficient to motivate participation in collective action without the promise of selective incentives.

\section{Study 1: Father versus Family}

If decisions about political violence are based more on moral than on instrumental considerations, instrumentally irrelevant factors should influence decision making. This experiment tested that prediction.

\section{Method}

Seven hundred and twenty Palestinian adults were recruited in 14 university campuses across the West Bank and Gaza to participate in a survey. Half of these participants were women and half were members of Hamas or Palestinian Islamic Jihad. Participants were asked the extent to which scenarios were certainly acceptable (coded "1"), somewhat acceptable (coded " 2 "), somewhat unacceptable (coded “3”), or certainly unacceptable (coded "4"). For example:

What if a person wanted to carry out a bombing (which some ... call suicide attacks) against the enemies of Palestine but his father becomes ill, and his family begs the chosen martyr to take care of his father, would it be acceptable to delay the attack indefinitely? 
What if a person wanted to carry out a bombing (which some ... call suicide attacks) against the enemies of Palestine but his family begs him to delay martyrdom indefinitely because there was a significantly high chance the chosen martyr's family would be killed in retaliation, would it be acceptable to delay the attack indefinitely?

\section{Results and Discussion}

Participants were inclined to believe that an indefinite delay of a suicide attack to save the entire family from probable death (mean [SD] $=2.348$ [1.186]) was more unacceptable than an indefinite delay of a suicide attack to look after an ill father (2.047 [1.069]; $z=-5.351$, $P<0.001$; by Wilcoxon signed rank test). Similarly, a 1-month delay of a suicide attack to save the entire family from probable death was rated as more unacceptable (2.726 [1.14]) than a 1 -month delay to look after an ill father $(2.591$ [1.106]; $z=-2.483, P=0.013$; by Wilcoxon signed rank test). Clearly, these results show that when people are reasoning between duty to war or to family, they are not making instrumental decisions but rather decisions based on perceptions of moral obligations that can change as a result of instrumentally irrelevant alterations in context.

\section{Study 2: Do Selective Incentives Constitute Taboo Trade-offs?}

To investigate the role of selective incentives versus collective commitment more directly, we examined whether ordinary people in a violent intergroup conflict believe that it is permissible or taboo to offer selective material incentives to combatants. Clearly, for selective incentives to motivate participation, the offer of such incentives should be permissible. If that were the case, people should encourage measuring the commitment of combatants along instrumental metrics, encouraging the use of material rewards to motivate participation. Alternatively, if participation is motivated by parochial altruism, ordinary people should regard material- selective incentives for participation in violent collective action as a "taboo trade-off" 35 as it entails measuring moral commitments along an instrumental metric. Furthermore, if this were the case, greater material incentives, which make the taboo nature of the trade-off more salient, should provoke stronger rejection of the trade-off. ${ }^{6-9}$

\section{Method}

To test these alternate hypotheses, we ran an experiment that was integrated in a survey of a representative sample of 1266 Palestinian Mus$\lim$ adults (51\% women, 49\% men; median age $=34)$ living in the West Bank $(63 \%$ of the sample) and Gaza (37\%). The survey was run by the Palestinian Center for Policy and Survey Research and was conducted face-to-face in the participant's homes (for greater detail of the survey methodology see www.pcpsr.org). The survey included a range of questions dealing with values, experiences under the Israeli occupation, and the way participants reasoned about political violence. To measure whether it was permissible or taboo in Palestinian society to think about material gains of involvement in acts of violence against the Israeli occupation, we asked,

In your view would it be acceptable for the family of a martyr to request compensation in the amount ofJD (Jordanian Dinars) after their son carried out a martyrdom operation? Would it be certainly acceptable, acceptable, unacceptable, or certainly unacceptable?

We randomly varied between participants the amount of money requested in this scenario: JD10,000, JD100,000, or JD1,000,000. To test the effect of the experimental manipulation, we scored participants' responses from 1 (certainly acceptable) to 4 (certainly unacceptable).

\section{Results and Discussion}

Across experimental conditions more than $90 \%$ of the sample regarded a request for compensation, regardless of the amount, to be 


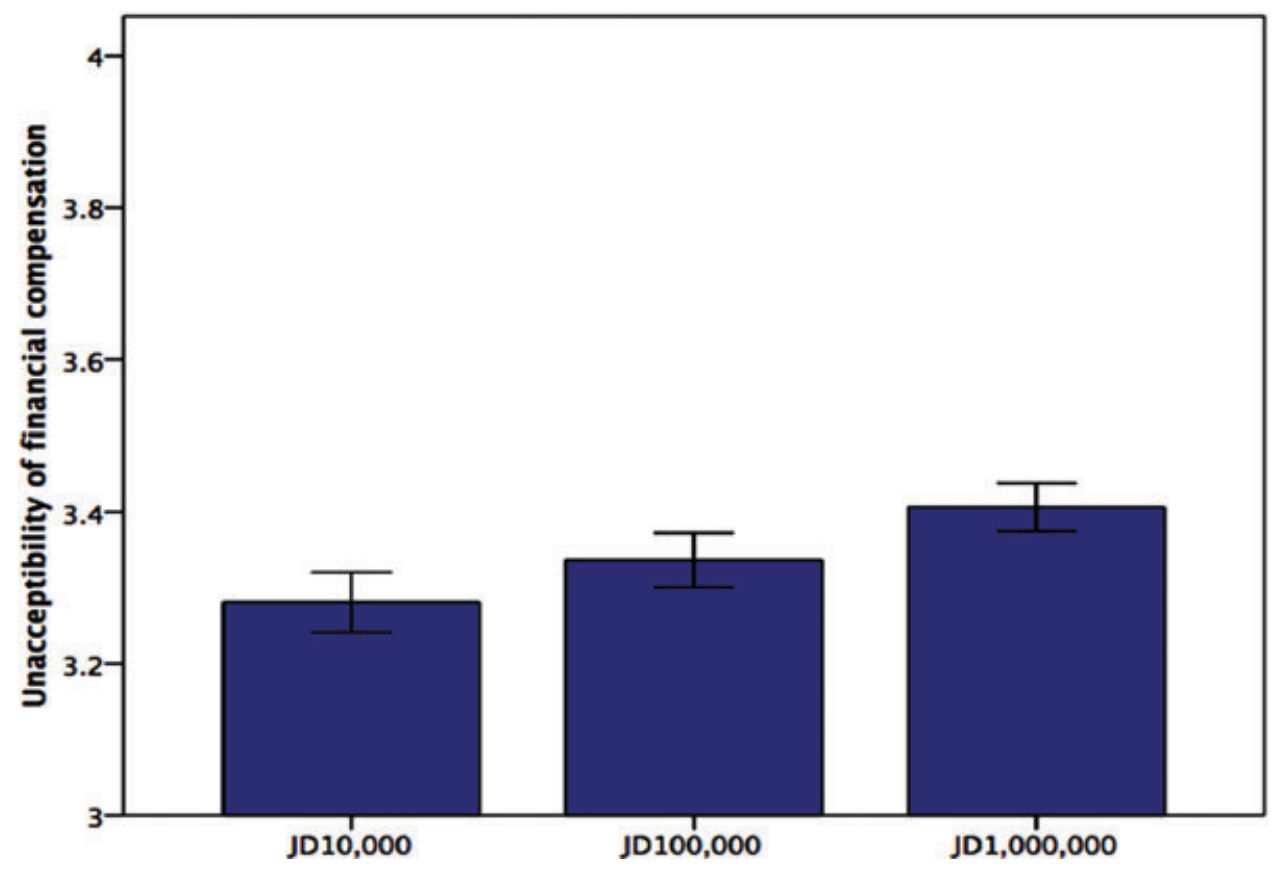

Figure 1. Mean ratings of how unacceptable it is for a martyr's family to request financial compensation as a function of the amount of compensation requested. Error bars show SEM. Values in Jordanian Dinars (JD).

unacceptable. This indicates that it is not normative to think about martyrdom in material terms. Analysis of variance indicated a significant linear trend $($ JD10,000 < JD100,000 < JD1,000,000) such that as the amount of financial compensation increased, so too did the perception that the request was unacceptable; $F(1,1187)=6.06, P=0.014$ (see Fig. 1$)$.

These results are inconsistent with the selective incentives explanation but consistent with the parochial altruism explanation for participation in violent collective action. Participants appeared to regard the request for financial compensation in exchange for the sacrifice of a martyr's life as taboo. Moreover, as the monetary amount requested increased so did disapproval ratings. However, alternative explanations for these findings remain. First, the wording of the question may have biased the results somewhat as referring to martyrs and martyrdom explicitly invokes a concept of sacrifice. Second, as mentioned earlier, it is possible that selective incentives are nonmaterial goods, such as reputation and status. It may be that, in Palestinian society, participation in collective political violence is motivated by nonmaterialselective incentives even as material-selective incentives are taboo. Third, the answers that people gave may be thought of as posturing rather than reflecting "true" opinions. This is a problem common to all studies of potential, actual, or past combatants; participants are motivated to deny real motivations to themselves and others and to substitute them. Put simply, the narratives people construct about political violence may simply not be true.

\section{Study 3: An Indirect Test of Selective Incentives versus Parochial Altruism as Motivators for Participation in Violent Collective Action}

Because direct investigation of motives to participate in collective action is particularly 
vulnerable to posturing, we present an investigation of the relationship between value priorities and participation in political violence. Values are general beliefs about desirable end states that represent motivational goals. ${ }^{36-38}$ Values constitute an excellent indirect means of investigating the importance of different types of motivations. For values to influence an individual's behavior, they must be first primed or activated and must also be of central importance to that individual. ${ }^{39}$ Thus, if, for instance, a positive relationship were found between self-enhancement values (which include social power, authority, wealth, personal success, and ambition) $)^{40}$ and participation in political violence, we could suppose that (a) participation or intentions to participate in collective actions would indicate that selective incentives to participate are sufficiently salient in the environment to prime self-enhancement values and (b) that self-enhancement motives disproportionately motivate participants, compared to nonparticipating supporters. No relationship between self-enhancement values and participation would imply either the absence of selective incentive cues or their irrelevance to decision making.

If, on the other hand, participation in violent collective action is driven by parochial altruism, then participation would be a positive function of the salience and importance of parochial incentives, such as security, tradition, and conformity, and a negative function of universalism values, such as broadminded, equality, and peace. ${ }^{40}$

\section{Method}

The research instrument was distributed via an anonymous mailing to a random sample of 3000 Jewish residencies in the West Bank to ensure anonymity of responses. Although many Jewish residents of the Israeli-occupied West Bank moved there from Israel for financial reasons, the community as a whole, typically referred to as settlers, is politically active with a history of involvement in nonstate polit- ical violence. ${ }^{41}$ A self-addressed stamped envelope accompanied the research instrument so that respondents could return the questionnaire anonymously. The response rate was $27 \%$ for all questionnaires sent to the correct address, resulting in a sample of 656 Jewish adults $(63 \%$ male, $37 \%$ female). Return rates have little impact on the validity of responses provided that the sample is representative of the population on significant dimensions. ${ }^{42,43}$ Our sample was representative of the Jewish population of the West Bank in terms of religious and political identities.

Our dependent variables were willingness to violently attack Palestinians or other Israelis who were attempting to enforce a forced evacuation of settlements. Respondents were asked to indicate whether they intended to engage in each behavior in the event that their settlement was to be dismantled in the context of a peace agreement (coded: "0" unwilling or " 1 " willing for each act). We regressed willingness to participate on value priority scores, which were measured using Schwartz's Portrait Questionnaire. ${ }^{40}$ This questionnaire consists of 27 questions each asking about a specific value. Each question is a portrait of an individual (for example, "Being very successful is important to him/her. He/she likes to impress other people."), and a respondent is asked to rate his or her similarity to the portrait on a six-point scale (from "very much like me" to "not at all like me"). Scores for each specific marker of different value types or themes were then averaged to produce a scale. The individual values representing "universalism" (alpha $=0.78$ ), "benevolence" (alpha = 0.76), "parochialism" (alpha $=0.80)$, and "self-enhancement" (alpha $=0.80)$ all formed reliable scales.

\section{Results and Discussion}

Reports of future intentions revealed a politically active sample. To act against the forced evacuation of their settlement, over $10 \%$ of participants $(n=67)$ reported a willingness to participate in violent attacks against Palestinians 
and $6.4 \%(n=42)$ were willing to participate in violent attacks against Israelis. While only a minority of Jewish residents were willing to participate in violent attacks, extrapolating the findings to a population approaching 250,000 indicates the seriousness of the issue. For example, if we assume an adult population of 100,000, approximately 10,000 may be willing to engage in violent attacks against Palestinians in the event of forced evacuation and approximately 6400 to attack other Israelis under the same conditions.

Logistic regressions showed no relationship between self-enhancement scores and willingness to attack Palestinians (Wald $=0.11$, NS) or Israelis (Wald $=0.6$, NS) but showed a positive relationship between conservatism scores and willingness to participate in acts of political violence. For every one unit increase on conservatism scores, the predicted odds of a person being willing to violently attack Palestinians increased by a multiplicative factor of 1.93 Wald $=9.52,95 \%$ confidence interval [CI] for Odds Ratio = 1.29-2.93, $P<.01$ ). Similarly, for every one unit increase on conservatism scores, the predicted odds of a person being willing to violently attack other Israelis increased by a multiplicative factor of 1.97 Wald $=7.18,95 \%$ CI for Odds Ratio $=1.2-3.23, P<.01)$. In other words, with every unit increase on the conservative score, the odds of participating in violent action are almost doubled.

It appears that values representing collective incentives are salient in the context of decisions to participate in collective actions and that participants are disproportionately motivated by such values. These results are striking, suggesting either that selective incentives are not particularly important to participants in some situations, such as those that underlie seemingly intractable cultural or political conflict, or at least that they are not incrementally motivating with respect to participation in collective actions within this community. Significantly, these findings have been recently replicated in a survey of Palestinians living in the
West Bank where willingness to participate in high-sacrifice actions to resist the Israeli occupation was negatively correlated with selfenhancement values but positively correlated with communal values.

\section{General Discussion}

Three studies carried out in the West Bank and Gaza suggested that people do not participate in violent political action in response to individual-level selective incentives. In Study 1, we showed that Palestinians tended to reason about political violence in a noninstrumental manner by showing more disapproval over a delay of a martyrdom attack to rescue an entire family than over a delay of a martyrdom attack to take care of an ill father. In Study 2 , we demonstrated that ordinary people regard material-selective incentives for participating in acts of martyrdom as taboo. The more money families requested in compensation for their son's martyrdom, the more intensely people disapproved of the request. In a third study of Israeli settlers, recently replicated by Nicole Argo with a Palestinian sample, selfenhancement motives (such as power) were unrelated (or negatively related) to willingness to participate in violent collective action. Instead, participation in violent collective action seems to be motivated by communal concerns; the greater the priority given to communal values, the more likely an individual was to be willing to participate in violent collective action. Such causes may of course be material; people may fight to defend an essential water resource. However, as we have shown previously, communal causes are often purely symbolic in nature, involving sacred values. ${ }^{6}$

We might question whether this empirical case study is relevant to other contexts, such as Iraqi opposition to American occupation, interethnic riots in Southeast Asia, or civil wars in African countries. In some circumstances, people might rebel as a function of immediate or delayed selective incentives. However, we do 
argue that our findings demonstrate that participation in collective political actions need not be in response to selective incentives. People will engage in costly and potentially deadly behaviors, they will be ready to kill and to die, solely to further collective goals, regardless of the presence of personal selective incentives.

These findings paint the picture of the parochially altruistic political actor rebelling to advance a cause in a way that is unrelated to personal ambitions, or in a way that is evidence of an abandonment of personal ambitions. It appears that choices people make in violent intergroup conflicts, from whether to accept a compromise to whether individuals commit themselves to violent collective action, are bound by moral commitments to collective interests.

\section{Acknowledgments}

We thank Hammad Sheikh and Kate Jassin for their helpful suggestions. This work was supported by the National Science Foundation (SBE-0527396 and BCS-827313) and the Department of Defense Multidisciplinary University Research Initiative (AOR-MURI W911NF-08-1-0301 and AFOSR FA9550-051-0321).

\section{Conflicts of Interest}

The authors declare no conflicts of interest.

\section{References}

1. Olson, M. 1965. The Logic of Collective Action: Public Goods and the Theory of Groups. Harvard University Press. Cambridge, MA.

2. Popkin, S. 1979. The Rational peasant: The Political Economy of Rural Society in Vietnam. University of California Press. Berkeley, CA.

3. Lichbach, M. 1994. What makes rational peasants revolutionary? Dilemma, paradox, and irony in peasant collective action. World Polit. 48: 383-418.

4. Lupia, A. \& G. Sin. 2003. Which public goods are endangered?: How evolving communication technolo- gies affect the logic of collective action. Public Choice 117: 315-331.

5. Weinstein, J. 2004. What makes rational peasants revolutionary? Dilemma, paradox, and irony in peasant collective action. Retrieved May 1, 2004, from https://upload.mcgill.ca/rgchr/weinstein.pdf

6. Ginges, J., A. Atran, D. Medin \& K. Shikaki. 2007. Sacred bounds on rational resolution of violent political conflict. Proc. Natl. Acad. Sci. USA 104: 7357-7360.

7. Ginges, J., \& S. Atran. 2009. Non-instrumental reasoning over sacred values: An Indonesian field experiment. In Psychology of Learning and Motivation, Vol. 50: Moral fudgment and Decision Making. D.M. Bartels, C.W. Bauman, L.J. Skitka \& D.L. Medin, Eds.: Academic Press. San Diego, CA.

8. Atran, S., R. Axelrod \& R. Davis. 2008. Sacred barriers to conflict resolution. Science 317: 1039-1040.

9. Ginges, J. \& S. Atran. 2008. Humiliation and the inertia effect: Implications for understanding violence and compromise in intractable intergroup conflicts. f. Cogn. Cult. 8: 281-294.

10. Bowles, S. 2006. Group competition, reproductive leveling and the evolution of human altruism. Science 314: 1569-1572.

11. Choi, J.K. \& S. Bowles. 2007. The co-evolution of parochial altruism and war. Science 318: 636640.

12. Collier, P. \& A. Hoeffler. 2004. Greed and grievance in civil war. Oxford Econ. Pap. 56: 563-595.

13. Fearon, J. \& D. Laitin. 2003. Ethnicity, insurgency and civil war. Am. Polit. Sci. Rev. 97: 75-90.

14. MacGulloch, R. 2004. The impact of income on the taste for revolt. Am. J. Polit. Sci. 48: 830-849.

15. Jost,J.T., M.R. Banaji \& B.A. Nosek. 2004. A decade of system justification theory: Accumulated evidence of conscious and unconscious bolstering of the status quo. Polit. Psychol. 25: 881-920.

16. Sidanius, J. \& F. Pratto. 1999. Social Dominance: An Intergroup Theory of Social Hierarchy and Oppression. Cambridge University Press. New York, NY.

17. Tajfel, H. 1981. Human Groups and Social Categories. Cambridge University Press. Cambridge, MA.

18. Tropp, P.R. \& A.C. Brown. 2004. What benefits the group can also benefit the individual: Group enhancing and individual enhancing motives for collective action. Group Process. Interg. 7: 267-282.

19. Muller, E.N. \& K.-D. Opp. 1986. Rational choice and rebellious collective action. Am. Polit. Sci. Rev. 80: 471-487.

20. Muller, E.N., H.A. Dietz \& S.E. Finkel. 1991. Discontent and the expected utility of rebellion: The case of Peru. Am. Polit. Sci. Rev. 85: 1261-1284.

21. Einwohner, R.L. 2003. Opportunity, Honor, and Action in the Warsaw Ghetto Uprising of 1943. Am. F. Sociol. 109: 650-675. 
22. Van Vugt, M. 2001. Community identification moderating the impact of financial incentives in a natural social dilemma: Water conservation. Pers. Soc. Psychol. B 27: $1440-1449$.

23. Van Vugt, M. \& C.M. Hart. 2004. Social identity as social glue: The origins of group loyalty. 7. Pers. Soc. Psychol. 86: 585-598.

24. Devos, T. \& M.R. Banaji. 2003. Implicit self and identity. Ann. N. Y. Acad. Sci. 1001: 177-211.

25. Greenwald, A.G. \& S.D. Farnham. 2000. Using the implicit association test to measure self-esteem and self-concept. 7. Pers. Soc. Psychol. 79: 1022-1038.

26. Smith, E.R. \& S. Nenry. 1996. An in-group becomes part of the self: Response time evidence. Pers. Soc. Psychol. B 22: 635-642.

27. Turner, J.C., P.J. Oakes, S.A. Haslam \& C. McGarty. 1994. Self and collective - cognition and social context. Pers. Soc. Psychol. B 20: 454-463.

28. Turner, J.C. \& P.J. Oakes. 1997. The socially structured mind. In The Message of Social Psychology: Perspectives on Mind in Society. C. McGarty \& S.A. Haslam, Eds. Blackwell Publishers. Oxford, UK.

29. Sturmer, S. \& B. Simon. 2004. The role of collective identification in social movement participations: A panel study in the context of the German gay movement. Pers. Soc. Psychol. B 30: 263-277.

30. Barnes, S.H., \& M. Kaase. 1979. Political Action: Mass Participation in Five Western Democracies. Sage. Beverly Hills, CA.

31. Grant, P.R. \& R. Brown. 1995. From ethnocentrism to collective protest: Responses to relative deprivation and threats to social identity. Soc. Psychol. Quart. 58: 195-211.

32. Guimond, S. \& L. Dube-Simard. 1983. Relative deprivation theory and the Quebec nationalist movement: The cognition-emotion distinction and the personal-group deprivation issue. 7. Pers. Soc. Psychol. 44: $526-535$.

33. Muller, E.N. 1972. A Test of a Partial Theory of Political Violence. Am. Polit. Sci. Rev. 66: 928-959.

34. Runciman, W.G. 1966. Relative Deprivation and Social Fustice. University of California Press. Berkeley, CA.

35. Fiske, A.P. \& P.E. Tetlock. 1997. Taboo trade-offs: Reactions to transactions that transgress spheres of justice. Polit. Psychol. 18: 255-297.

36. Feather, N.T. 2004. Value correlates of ambivalent attitudes toward gender relations. Pers. Soc. Psychol. B 30: $3-12$.

37. Schwartz, S.H. \& W. Bilsky. 1987. Toward a universal psychological structure of human-values. 7. Pers. Soc. Psychol. 53: 550-562.

38. Schwartz, S. H. 1994. Are there universal aspects in the structure and contents of human-values. F. Soc. Issues 50: 19-45.

39. Verplanken, B. \& R.W. Holland. 2002. Motivated decision making: Effects of activation and self-centrality of values on choices and behavior. 7. Pers. Soc. Psychol. 82: $434-447$.

40. Schwartz, S.H., G. Melech, A. Lehmann, et al. 2001. Extending the cross-cultural validity of the theory of basic human values with a different method of measurement. 7. Cross Cult. Psychol. 32: 519-542.

41. Weisburd, D. 1989. Jewish Settler Violence: Deviance as Social Reaction. Pennsylvania State University Press. University Park, PA and London, UK.

42. Keeter, S., C. Miller, A. Kohut, et al. 2000. Consequences of reducing nonresponse in a national telephone survey. Public Opin. Quart. 64: 125-148.

43. Pew Research Center. 2004. Polls face growing resistance, but still representative. Retrieved 12 May, 2004, from http://people-press.org/reports/display. php3?ReportID=211 